\title{
The Compensation Strategies of an Advanced and a Less Advanced Language Learner: A Case Study
}

\author{
Ana Belén Cabrejas-Peñuelas \\ Instituto Interuniversitario de Lenguas Modernas Aplicadas, Universidad de Valencia, Blasco Ibáñez 32, Valencia \\ 46010, Spain \\ Email: ana.belen.cabrejas@uv.es
}

\begin{abstract}
This article presents the findings of a study that aims at investigating the compensation strategies used by an expert and a less expert language learner. Analyses of the think-aloud protocols, writing plans, drafts, the video recordings of the writing sessions and the follow-up interviews have given as a result a whole range of strategies. Compensation strategies have been found to be useful to make up for lack of linguistic knowledge and to keep the composing going. The advanced and less advanced learners have been found to use very similar strategies; however, while the advanced learner showed a careful orchestration of strategies leading to successful prose, the less expert used several strategies in a linear fashion that did not have good results for the quality of her essay. The results may have implications for teaching less able students.
\end{abstract}

Index Terms - expert learners, less expert learners, compensation strategies, L2 writing, think-aloud protocol

\section{INTRODUCTION}

Current studies investigating language learners' strategy use conclude that all students use strategies to learn the target language. Of those, compensation strategies are widely employed to compensate for lack of linguistic knowledge, which include using a new grammatical structure; revising extensively; reducing information (Uzawa \& Cumming, 1989); rehearsals (Raimes, 1987); rereading for retrospective or prospective functions, the former as a way of assessing that the words chosen capture the writers' intended meaning and the latter to compare their writing against the topic assignment and the ideas the writers plan to develop (Manchón et al., 2000b; Wolfersberger ,2003; Murphy \& Roca de Larios, 2010); translation (Cumming, 1989; Swain \& Lapkin, 1995; Wolfersberger, 2003); resorting to the L1 (Woodall, 2002; Beare \& Bourdages, 2007); generating and assessing lexical alternatives (Cumming, 1989; Swain \& Lapkin, 1995; Wang, 2003; Sasaki, 2004); feeling for the language through sound and sense (Swain \& Lapkin, 1995); using their L2 knowledge; guessing; substituting a lexical item; coining words; referring to the dictionary (Wolfersberger, 2003) and backtranslation (Manchón et al., 2000a; Wang, 2003; Wolfersberger, 2003). Some researchers have also reported that advanced learners differ from less advanced ones in how they use compensation strategies. Knowledge of how these types of students differ should provide teachers with tools to help their weaker learners. The purpose of this study is, therefore, to report on how an advanced and an intermediate student of English as a foreign language differ in the compensation strategies they use.

\section{THEORETICAL FRAMEWORK}

Researchers focusing on the L2 composing process have been concerned with different approaches at different times. Early L2 studies focus on L2 behaviors when composing, while later theories study different types of L2 writers or the features unique to L2 composing. Early bibliography on ESL writing deals with some general assumptions, such as the fact that L2 writings share similarities with L1 writings, the notion of transferability of writing abilities and strategies between the L1 and L2 and the influence of task complexity on the quality of the text. Among the later theories, psycholinguistic studies of L2 writing have tried to describe the specific skills needed for L2 writing. L2 learner variables have been the focus of attention, which includes the level of L2 linguistic knowledge (Carson et al., 1990; Yau, 1991; Pennington \& So, 1993; Sasaki \& Hirose, 1996) and writers' procedural knowledge (Jones \& Tetroe, 1987; Cumming, 1989).

Within the process-oriented trend, a major focus of investigation is the strategies L2 writers use while writing, since successful and unsuccessful writers have been found to differ especially in the quality and appropriateness with which the strategies are employed (Manchón, 2001, p. 49). The writing process is recursive, that is, writers constantly return to earlier stages of the process in order to carry out later ones. It is essentially a search for meaning that is aided with the use of writing strategies. Such strategies have been divided strategies into control mechanisms, which advanced writers employ to monitor the gist, the organization of their compositions and the linguistic expression, and problem-solving mechanisms, which entail the existence of a problem, a solution search process and the existence or not of a solution to 
the problem. Advanced and emergent planning (i.e. thinking about the content in advance or while writing) are two types of control mechanisms, while repetitions and rereadings of the text already composed are problem-solving mechanisms, which serve to make up for lack of linguistic knowledge, as pointed out by a number of investigations with EFL writers (Roca de Larios et al., 2001; Wolfersberger, 2003). Repetitions are used for compensating for the limited capacity of the working memory and rereadings for revision, planning or transcription purposes (Manchón, 2001, p. 56). Compensation strategies are defined as any strategy that is used to compensate for lack of linguistic knowledge. Compensation strategies can be applied at different levels - lexical, sentential and discourse/rhetorical levels - and with different general purposes: to maintain the same level of writing achieved in the L1 (translation, repetition, rehearsing, dictionary use, backtranslation, rereading, using a new grammatical structure, and revising extensively) and to complete the task within a given amount of time and without excessive cognitive effort (guessing, going by the sound, substituting a lexical item, coining words, reducing information, and using line numbers rather than copying) (Uzawa \& Cumming, 1989, p. 185).

Advanced and novice writers differ in how they compensate for their missing knowledge. Indeed, advanced writers make extensive reareadings of their texts and repeat to keep their writing going or for revision purposes; however, less advanced writers often do very little rereading or reread and repeat large chunks of text, but they do not have good overall results (Wolfersberger, 2003). These results indicate that L2 proficiency affects the use of L2 compensation strategies. A wealth of literature (Zamel, 1983; Arndt, 1987; Jones \& Tetroe, 1987; Raimes, 1987; Cumming, 1989; Cumming et al., 1989; Yau, 1991; Pennington \& So, 1993; Hirose \& Sasaki, 1994; Smith, 1994; Sasaki \& Hirose, 1996) has concentrated on finding out the role of L2 proficiency and the writer's procedural knowledge in L2 writing expertise. For example, Jones \& Tetroe (1987) compared the writing processes of a group of subjects writing in two languages and found that their students used the same planning strategies in both their L1 and L2. The results also indicated that the ESL writers' language proficiency affected the quantity, not the quality, of planning. Jones \& Tetroe further concluded that, if the planning models used when writing in the L2 had been transferred from the L1, lack of abstract planning could not be attributed to lack of L2 expertise. Instead, lack of L2 expertise affected the quality of the texts, but it did not interfere in the planning process. Similarly, for Cumming et al., (1989) the use of problem-solving strategies in the L1 and L2 was not related to second language proficiency, but to the learners' levels of writing expertise. It was however true that the higher the writing expertise and the writers' L2 proficiency level, the higher the grades in the compositions they obtained. These conclusions suggest that L2 proficiency has an important influence in explaining L2 writing ability.

There are however other studies (Carson et al., 1990; Yau, 1991; Pennington \& So, 1993) that add more support to the hypothesis that L2 proficiency plays a major role in L2 writing ability. For example, Carson et al. (1990), who examined the L1 and L2 reading and writing abilities of a group of ESL learners, claimed that there was a weak positive correlation between L1 and L2 writing scores; however, the correlation was stronger as the learners' L2 proficiency level increased. Also, Pennington \& So (1993) concluded that there was no relationship between process skill and product quality in the L2; instead "writing quality in an L2 was related to general proficiency level in that language" (p. 58). The results of the above studies have therefore not shed enough light on the role of L2 proficiency and the writer's procedural knowledge on L2 writing expertise. The present study aims at exploring the effects of language proficiency, amount of L2 writing experience and past instruction on L2 writers' use of compensation strategies. The two writers selected have different proficiency levels, differing amounts of writing experience and different past instruction and, thus, they should differ in how they compensate for their missing knowledge.

\section{RESEARCH QUESTIONS}

The following questions will be addressed:

a. What are the compensation strategies used by the advanced learner? And by the less advanced learner?

b. Do the L2 learners differ in how they use compensation strategies? How different are they?

\section{MATERIALS AND METHODS}

The current study attempts to investigate the compensation strategies used by an advanced and a less advanced language learner while writing an argumentative essay in English. It is part of a larger study that examined the composing processes of advanced and less advanced language learners in a Spanish setting.

\section{A. Participants}

Two students were selected from the student population at the University of Valencia (Spain). They were selected based on several criteria: the mean grade obtained in all academic terms or GPA (Grade Point Average), the grade in the latest writing course they had taken, the TOEFL score obtained for this study, their experience in writing in English and the opinions that their professors had of them. Alicia ${ }^{1}$ was considered an advanced learner and Eva an intermediate language learner. Eva was an EFL undergraduate student at the time of this study with limited contact with the English

\footnotetext{
${ }^{1}$ Pseudonyms have been used to refer to the writers.
} 
language except for in-class time and the requirements for the classes, which comprised readings and writing essays. The differences between the two participants were due to length of exposure to English, overall level of general education, writing experience, past instruction, and kinds of tasks (see Table 1). All these differences were likely to have contributed to their use of compensation strategies. Table 1 also provides background information for each writer, which includes academic status, age, writing course, course grade and GPA. "Writing Course" refers to the latest English class the students had taken and the grade they scored. GPA refers to the students' overall grade point average at the end of the academic year 2001. Both students took the TOEFL exam from the TOEFL Test Preparation Kit by the Educational Testing Service (1995) and scored as follows: Alicia obtained 613 and Eva 443. Alicia's score is equivalent to the $\mathrm{C} 2$ level according to the Common European Framework or proficiency level in the Cambridge examinations and Eva's score corresponds to the B1 level or pre-intermediate level.

TABLE 1.

BACKGROUND INFORMATION FOR THE WRITERS

\begin{tabular}{lll}
\hline \hline & Alicia & Eva \\
\hline \hline Academic status & Content and organization & Grammar \\
Age & 23 & 21 \\
Writing course & Poesy XIX and XX & English III \\
Course grade & A & C \\
GPA & A & C $^{+}$ \\
Writing experience & Wrote in three languages frequently, & Wrote not very often. \\
& Spanish, English and German. & \\
Past instruction & Use of a fixed structure. Her teachers & Her teachers intended students to write \\
& pointed out some errors: too long & error-free compositions. They taught the \\
& paragraphs and ideas not always clear. & importance of structure and using a plan. \\
Kinds of tasks & Narrative, descriptive and argumentative & Narrative and descriptive essays. \\
& essays. & \\
\hline \hline
\end{tabular}

\section{B. Materials and Procedure}

We collected data via different methods, including the writers' compositions, think-aloud protocols, interviews, questionnaires and the researcher's observations of the students' behaviors in the videotapes in the hope that a large number of data collecting methods helped to confirm or put into question the results obtained. The think-aloud protocols and the interviews were recorded and transcribed verbatim for further analysis. The writing assignment used required the students to compose an argumentative essay, which was hoped to stimulate "knowledge transformation" (Bereiter \& Scardamalia, 1987) and to involve greater use of compensation strategies due to its greater cognitive difficulty. The topic intended to be controversial and to involve two or more opposing positions. In the assignment, the topic was stated as follows: "The use of marijuana should be legalized", borrowed from Gaskill (1986). The students were told to write a well-developed composition arguing for or against the statement and to provide support for their positions.

The study that follows next combines two forms of verbal report - self-revelation and self-observation - in researching the writing process. In self-observations the learner reports what $\mathrm{s} / \mathrm{he}$ has done and s/he does so within a short or long period from the event, while in self-revelations (also known as "think-aloud protocols") the learner provides an ongoing report of his thought processes while writing his task. Think-aloud protocols are not influenced by time as they are concurrent with the actual writing and, hence, the effects of time are minimized. However, they may pose a load on writers' cognitive processes. In this study, the self-observations were obtained from interviews occurred immediately after the writing of the final draft, while the self-revelations came from having the students think aloud while writing. The writers were told in Spanish to write and verbalize everything that went through their minds as they wrote and were asked not to stop talking at any moment; however, no modeling of the method was provided so as not to influence their choice of language, as we were particularly interested in their choice of the mother tongue. A few minutes before the actual writing session, the procedure was explained and the writers tried it out in the first writing session, while the researcher carefully listened in and encouraged them to keep talking occasionally. The researcher left the room when the writers had clearly grasped the technique (usually a few minutes). It should be noted that the results of this study can only be applied to time-compressed tasks, as the writers had one hour and a half to complete their compositions. The protocols were collected, transcribed and then reviewed and analyzed for composing strategies. The interviews were carried out individually, were informal and lasted about forty-five minutes.

The results indicate that Alicia and Eva had two very different approaches to writing in English, which were corroborate by the observations of the writers and the think-aloud protocols (see Table 2). 
TABLE 2.

A SUMMARY OF ALICIA'S AND EVA'S INTERVIEWS

\begin{tabular}{|c|c|c|}
\hline & Alicia & Eva \\
\hline Teaching focus & Content and organization & Grammar \\
\hline $\begin{array}{l}\text { Writing processes } \\
\text { Written or mental outline }\end{array}$ & $\begin{array}{l}\text { Written outline. Little specificity } \\
\text { in her written outline }\end{array}$ & Written outline \\
\hline $\begin{array}{l}\text { Non-elaborated } \\
\text { Organization } \\
\text { Reader } \\
\text { Purpose in mind }\end{array}$ & $\begin{array}{l}\text { Yes } \\
\text { Yes, her teacher } \\
\text { Yes }\end{array}$ & $\begin{array}{l}\text { Yes } \\
\text { No } \\
\text { No }\end{array}$ \\
\hline Revising processes & & \\
\hline Global revisions & Yes & No \\
\hline $\begin{array}{l}\text { Time devoted to revise ideas to } \\
\text { make them clearer (out of } 100 \% \text { ) }\end{array}$ & $20 \%$ & $5 \%$ \\
\hline $\begin{array}{l}\text { Problems with the composition on the legalization of } \\
\text { marijuana }\end{array}$ & $\begin{array}{l}\text { Assessing whether the written text } \\
\text { matched her intended meaning; } \\
\text { connecting old and new ideas. }\end{array}$ & $\begin{array}{l}\text { Building grammatically } \\
\text { complex sentences; } \\
\text { vocabulary. }\end{array}$ \\
\hline
\end{tabular}

Taking into account the methodological recommendations made in previous investigations (Ericsson \& Simon, 1993) in the transcriptions of the subjects' verbalization non-verbal elements (hesitations, repetitions, paralinguistic features, and pauses) were also included, since they contribute to enrich the results. In addition, the following distinctions were made when preparing the protocols for analysis: a) distinction of the subjects' written text from the processes which generated it (planning, formulation and revision); b) identification of readings, repetitions and pauses, including the duration of such pauses; c) identification of any revisions made to the written text; and d) specification of off-task behaviors, such as drinking water, which may be indicative that the subject was thinking about the task at hand, and offtask comments, such as the time left for the end of the task, which may explain for example why a subject decided not to include any more arguments in his final version and, thus, recopied parts of his first draft. Once the transcriptions of the protocols had been made, the researcher created a coding scheme including the compensation strategies found in previous studies (see Table 3) and added "using line numbers rather than copying from her first draft". The analysis of the protocols was made by the researcher and an English graduate student, who transcribed 30\% of them. The interrater agreement was $78.05 \%$. When there was no agreement as to which strategy was being used, both raters checked and discussed the individual cases until they reached an agreement.

TABLE 3.

TYPES OF KEY COMPENSATION STRATEGIES

\begin{tabular}{|l|l|}
\hline \hline Compensation strategies (Manchón et al. 2000a; Raimes 1985; Sasaki 2004; Uzawa \& Cumming 1989; van Weijen et al. \\
2009; Wolfersberger 2003; Woodall 2002) \\
\hline \hline $\begin{array}{l}\text { 1. Strategies aiming at maintaining the same level of writing achieved in the L1 } \\
1 .\end{array} \quad$ Translation \\
2. & Repetition \\
3. & Rehearsing \\
4. & Dictionary use \\
5. & Backtranslation \\
6. & Rereading the text produced so far, the assignment sheet and the notes/outline \\
7. & Using a new grammatical structure \\
8. & Revising extensively \\
2. Strategies aiming at completing the task within a given amount of time and without excessive cognitive effort \\
9. & Guessing \\
10. & Going by the sound \\
11. & Substituting a lexical item \\
12. & Coining words \\
13. & Reducing information \\
14. & Using line numbers rather than copying from the first draft \\
\hline \hline
\end{tabular}

Two raters evaluated the subjects' compositions following the procedures specified by Jacobs et al., (1981). The raters were two Spanish professors at the University of Valencia who agreed to participate in this investigation. They were told to read the compositions twice, underline the mistakes and decide on the score for content, organization, vocabulary, language use, and mechanics. In case there was a discrepancy of more than two points, a third rater was consulted and the scores of the two closest raters were used. In order to judge the overall quality of the essays additional measures were used to analyze content, lexical complexity and grammatical accuracy: a) number of ideas to study the 
complexity of the content developed; b) number of paragraphs to assess syntactic complexity; c) lexical density ${ }^{2}$ to evaluate lexical complexity; and d) the ratio of the number of grammatical errors to the total number of sentences in a piece of writing to assess grammatical accuracy ${ }^{3}$ (see Table 4).

TABLE 4.

NUMBER OF IDEAS, PARAGRAPHS, MEASURES OF LEXICAL DENSITY, AND GRAMMATICAL ERRORS IN ALICIA'S AND EVA'S DRAFTS.

\begin{tabular}{lll}
\hline \hline & Alicia & Eva \\
\hline \hline Number of ideas expressed in the final draft & 12 & 5 \\
Number of paragraphs produced in the final draft & 11 & 6 \\
Measures of lexical density (NLex/N x 100) & $46.65 \%$ & $44.92 \%$ \\
Number of grammatical errors & 0.285 & 1.6 \\
\hline \hline
\end{tabular}

a NLex: number of lexical word tokens (nouns, adjectives, verbs, adverbs), N: number of all tokens.

The writers' dominant language while composing was also determined to find out about the writers' favored language. The results can be used to try to elucidate whether or not the variable "dominant language" in the composing process has a bearing on the language used for the compensation strategy of backtranslating. Manchón et al., (2000a, p. 18) define "dominant language" as "the language (L1 or L2) used by the writer to plan, monitor and evaluate the writing process". This variable was accounted for by first counting the total number of words in the protocol and the number of L1 and L2 words. The total number of words in the two drafts were counted and subtracted from the total number of words in the protocol. Next, the number of L2 words in the drafts was subtracted from the resulting number. Percentages of L1 and L2 words used in the composing process were then calculated. The data depict two distinct patterns of use: whereas Alicia's composing behavior was mainly verbalized in her L2, Eva showed a preference for her L1 (see Table 5).

TABLE 5.

DOMINANT LANGUAGE IN THE INFORMANTS' L2 COMPOSING

\begin{tabular}{lll}
\hline \hline Informants & Dominant language in L2 composing & \\
& L2 & L1 \\
\hline \hline Alicia & $61.22 \%$ & $38.78 \%$ \\
Eva & $43.91 \%$ & $56.09 \%$ \\
\hline \hline
\end{tabular}

\section{Results}

\section{Grades for the composition in this study}

Eva's scores for the composition reveal that her essay lacked overall quality, since she presented shortcomings at all levels - content, organization, vocabulary, language use, and mechanics (see Table 6). Also, she expressed few ideas in her draft, had few paragraphs and made many grammatical mistakes, which contributed to obscure meaning (see Table 4 above). In contrast, Alicia's essay had good overall quality in spite of some shortcomings in language use. The number of ideas and number of paragraphs in her text were indicative that Alicia tried to develop her argumentation with different ideas and these were deep and probing. The measure of lexical density was medium, which implies that it could be easily understood, and the ratio of the number of grammatical errors to the total number of sentences was low and, thus, the text was correct in general.

\section{L2 Strategies for maintaining the L1 level}

\section{Translation}

The most widely known compensation strategy used by novice L2 writers is translation from their L1 into their L2 (Raimes, 1985; Jones and Tetroe, 1987; Manchón et al., 2000a; Wolfersberger, 2003; Sasaki, 2004; van Weijen et al., 2009). During her composing processes, Eva used Spanish and English; however, her protocol reveals that her English was encased in Spanish because she was thinking in Spanish. Generating content in the L2 implied great cognitive effort, which explains why she used her L1 while planning and generating text and her ideas were then translated. It seems that her L2 level was not high enough to write in English and, yet, it was not low enough to write her essay in Spanish and then translate it into English:

(1) [writes \& talks] los famosos coffee-shops ... the famous coffee-shops ... donde cannabis o marihuana ... [writes] where cannabis is freely available ... [talks] no han hecho nada por reducir el crimen [talks \& writes] have done anything to reduce crime ¿o criminality? Criminality.

Eva's L1 helped her to retrieve lexical items, but also grammatical structures and then repeated them in the hope that the terms in the L2 would come to her mind:

(2) [talks] porque si el gobierno permite su uso ... [talks \& writes] if the government permits ... its freely ... [talks] its freely ... consumition? Consumición ... consumption [talks \& writes] con-sump-tion [checks the dictionary \& talks]

\footnotetext{
${ }^{2}$ The formula for calculating lexical density was adapted from Laufer and Nation (1995) who measured vocabulary size and use in second language written production. The formula was as follows: Lexical density = number of different lexical words $\mathrm{x} 100 /$ total number of tokens

${ }^{3}$ As in Li, Y. (2000: 236), the ratios were calculated to control for texts of unequal length in the writing samples. The formula used was as follows:

Number of grammatical errors $=$ number of grammatical errors $/$ total number of sentences
} 
consumición ... consumption, yo diría consumo, consumo, consumption. OK. [writes] consumption [talks] consumption ... what? [she's forgotten what she wanted to say]

In excerpt (2) Eva deployed some strategies: translation, repetition, word coining, dictionary use and use of synonyms and, yet, they were ineffective because the individual strategies were inappropriately orchestrated. She concentrated on spelling matters rather than meaning and, thus, she forgot what she wanted to say. Despite using translation widely, Eva commented on the danger of translating from her native language into English if she relied on Spanish too much:

INTERVIEW: "Intento no pensar en español cuando escribo en inglés, aunque lo utilizo cuando necesito ideas o cuando estoy en medio de un párrafo y no me sale."

[I try not to think in Spanish when I'm writing in English; however, I use it when I need ideas or when I'm in the middle of a paragraph and I can't get it done]

TABLE 6.

SUMMARY OF EVA'S AND ALICIA'S SCORES BASED ON JACOBS ET AL. (1981)

\begin{tabular}{|c|c|c|c|}
\hline $\begin{array}{l}\text { SCORES } \\
\text { EVA }\end{array}$ & Rater \# 1 / Rater \# 2 & $\begin{array}{l}\text { SCORES } \\
\text { ALICIA }\end{array}$ & "Rater \# 1 / Rater \# 2 \\
\hline $\begin{array}{l}\text { Vocabulary } \\
13 / 13 \\
\text { Language use } \\
10 / 10\end{array}$ & $\begin{array}{l}\text { R1 \& 2: VERY POOR: does not show } \\
\text { knowledge of subject, non-substantive, not } \\
\text { pertinent, OR not enough to evaluate. } \\
\text { R1: VERY POOR: does not communicate, } \\
\text { no organization, OR not enough to evaluate. } \\
\text { R2: FAIR TO POOR: non-fluent, ideas } \\
\text { confused or disconnected, lacks logical } \\
\text { sequencing or development. } \\
\text { R1 \& 2: FAIR TO POOR: limited range; } \\
\text { frequent errors of word/idiom form, choice, } \\
\text { usage; meaning confused or obscured. } \\
\text { R1 \& 2: VERY POOR: virtually no mastery } \\
\text { of sentence construction rules, dominated } \\
\text { by errors, does not communicate, OR not } \\
\text { enough to evaluate. } \\
\text { R1 \& 2: GOOD TO AVERAGE: occasional } \\
\text { errors of spelling, punctuation, } \\
\text { capitalization, paragraphing but meaning } \\
\text { not obscured. }\end{array}$ & $\begin{array}{l}\text { Content } \\
30 / 30 \\
\text { Organizat. } \\
17 / 17 \\
\text { Vocabulary } \\
17 / 17\end{array}$ & $\begin{array}{l}\text { R1 \& 2: EXCELLENT TO VERY GOOD: } \\
\text { knowledgeable, substantive, thorough } \\
\text { development of thesis. } \\
\text { R1 \& 2: GOOD TO AVERAGE: somewhat } \\
\text { choppy, loosely organized but main ideas } \\
\text { stand out, limited support, logical but } \\
\text { incomplete sequencing. } \\
\text { R1 \& 2: GOOD TO AVERAGE: adequate } \\
\text { range; occasional errors of word/idiom } \\
\text { form, choice, usage but meaning not } \\
\text { obscured. } \\
\text { R1: FAIR TO POOR: major problems in } \\
\text { simple/complex constructions; frequent } \\
\text { errors; meaning confused or obscured. } \\
\text { R2: GOOD TO AVERAGE: effective but } \\
\text { simple constructions; minor problems in } \\
\text { complex constructions; meaning seldom } \\
\text { obscured. } \\
\text { R1 \& 2: EXCELLENT TO VERY GOOD: } \\
\text { demonstrates mastery of conventions; few } \\
\text { errors }\end{array}$ \\
\hline
\end{tabular}

\section{Repetition}

Repetition of words and little phrases was also employed by the less advanced L2 writers, mainly because it is simple. Writing represented such a strenuous effort for Eva that she repeated trying to find the words she needed to complete her sentences:

(3) [Starts to write her first draft] [talks and writes] Many people hold strong views ... [repeats] many people have strong views [checks her notes] many people hold strong views ... [writes and talks] for and against ... for an against ... for and against [checks her notes] [...].

Also, as Eva was planning as she was going, she repeated words or little phrases in an attempt to find how to continue, to find the right word and the exact form of words. However, she overused repetition, because she did not know what she wanted to say and had to resort to her notes to find a way of continuing. Such notes were produced while planning and were a kind of blueprint for the ideas that she later developed in her essay.

Unlike Eva, Alicia repeated very few times and did so in an attempt to put her thoughts onto paper, since she planned as she was writing. Such repetitions helped her to find the words she needed and seemed not to be due to working memory limitations, since she managed her L2 fluently and efficiently as successful English writers do.

(4) [reads] However, I would like to express a compromise between both parts, which should prevent ... (2') [talks] should prevent ... [talks \& writes] legalization from ... (2') worsening the situation of ... (2') marijuana consume.

\section{Backtranslation}

As in other studies (Manchón et al., 2000a; Wang, 2003; Wolfersberger, 2003), Eva backtranslated from her L2 back into her L1. Cumming (1990, p. 495) explained backtranslation as follows:

If unsure of linguistic (especially lexical) items in the second language, these writers frequently back-translated (from their second language to their mother tongue) to verify their intended sense. The tendency of writers to do such back translation confirms that conceptual relationships were equated, cognitively, across first and second languages. 
Manchón et al. (2000a, p. 24-5) distinguished between direct translation of the segment rescanned (DT), translation with omissions (OM) and paraphrasing (PR), all of which were grouped under the name "backtracking through the L1". Direct translation is a word-for-word translation of the writers' text from the L2 back into their L1. Translation with omissions consists in a translation into the L1 omitting part of the segment translated. Finally, paraphrasing involves the writer taking a mental picture of the segment that he is going to translate into the L1 and rewording the original text. This study provides evidence for a more sophisticated type of translation, which involves paraphrasing the information in the $\mathrm{L} 2$ and omitting part of it using the $\mathrm{L} 1\left(\mathrm{PR}_{\mathrm{L} 2}+\mathrm{OM}\right)$. For Eva, this study only reports instances of direct translation of the already written text, as in (5) and the written notes/outline, because she did not go back to reread or translate beyond the sentence she was working on:

(5) TEXT: ... in general the effects produced are similar although there is a fundamental difference between them

PROTOCOL: ... in general the effects produced are similar ... the effects produced are similar ... marijuana ... [...] [Talks] although there is a difference between them ... [writes \& talks] but although ... there is a fundamental difference between them ... una diferencia importante entre ellas ... una diferencia importante entre ellas ...

[PROTOCOL: there is a fundamental difference between them ... an important difference between them ... an important difference between them ....

Eva's protocols indicate that she translated from Spanish into English to generate content and then backtranslated to verify that the words chosen conveyed her ideas, as in (5) above, a strategy also observed in Wang's (2003) and Wolfersberger's (2003) studies.

In contrast, Alicia did not employ direct translation, translation with omissions and paraphrasing from her L2 back into her L1. Instead, she made use of paraphrasing in the L2 plus omission in the L1 $\left(\mathrm{PR}_{\mathrm{L} 2}+\mathrm{OM}\right)$ :

(6) TEXT $2^{\mathrm{ND}}$ DRAFT: In favour of my opinion, I will not make use of some arguments that have been defended by consumers to support marijuana legalisation, like the claim that it does not create any dependence or that it even has some benefits in the treatment of illnesses or pains, because they are mere hypotheses that medicine and doctors have not confirmed yet, or the side-effects of which have not been sufficiently studied.

PROTOCOL: [Rewrites a paragraph in her $1^{\text {st }}$ draft $\&$ talks] I'm going to say ... In favour of my opinion, (comma) I will not make use of some arguments ... of some arguments that have been defended by consumers to support marijuana legalisation ... marijuana legalization, (comma) like the claim that it does not create any dependence [talks] uff, qué tarde, me encerrarán aquí ... any dependence [writes] or that it even has some benefits in the treatment of illnesses or pains, [talks] I'll skip a piece because it is superfluous I will only use some arguments like the claim de esto y de lo otro [talks \& copies] because they are mere hypotheses.

[PROTOCOL: [...] phew, it's so late, I'll get locked here ... [...] [talks] I'll skip a piece because it is superfluous I will only use some arguments like the claim about this and that [talks \& copies] because they are mere hypotheses.

Alicia made use of her L1 and L2 to decompose her already written text. She reworded her text by first omitting information in the L2 ("that have been defended by consumers to support marijuana legalisation") and then by substituting information. In this way, writers "may be representing to themselves not only the surface text, but also the text they have developed in their heads" (Manchón et al., 2000a, p. 26). However, Alicia also omitted information through her L1. The key idea is triggered by the word "claim" and the translation omits parts of the already written text. It seems therefore that more advanced learners of English do not need to backtranslate to decompose the text in terms of ideas developed and to get a mental picture of the text written so far.

Rehearsal and going by the sound

Rehearsing, defined as "voicing ideas on content and trying out possible ideas" (Raimes, 1985, p. 242), is possible thanks to the think-aloud protocol and can be found orally and in writing with a grammatical purpose or to check the ideas on an audience. Raimes $(1985 ; 1987)$ commented on the compensatory purpose of rehearsal. In this study, both the advanced and the less advanced learners used this technique; however, Eva rehearsed more frequently (Eva rehearsed 11 times and Alicia 9 times). Like other studies (Raimes, 1987; Wolfersberger, 2003), the present study does not find correlation between amount of rehearsing and writing quality and even finds counterproductive results. Eva started her sentences and rehearsed to express her ideas in English once some words had already been written. She also rehearsed to find individual words and the syntax needed to put down onto paper the ideas that were clear to her in her L1:

(7) "[writes \& talks] taken ... take o taken? Take ... the case of Holland which is one ..."

On occasions, when rehearsing, she seemed to make a decision based on the sound of the words, as in (8). However, as a rule Eva preferred to check the dictionary.

(8) [Talks \& writes] People ... [talks] la gente estará bajo los efectos de la marijuana, under the effects? under the effects no me suena mucho, over the effects? [Talks \& writes] People will be under the effects [talks] no me suena mucho, luego lo busco.

[[Talks \& writes] People ... [talks] people will be under the effects of marijuana, under the effects? under the effects doesn't sound familiar to me, over the effects? [Talks \& writes] People will be under the effects [talks] it doesn't sound familiar to me, I'll look it up later.]

Although advanced learners may also use the strategies of translation, rehearsing, backtranslation and repetition, they use them combined with other strategies either simultaneously or in sequence, which results in good quality essays 
(Macaro, 2006, p. 327). In excerpt (9) Alicia rehearsed to decide on the adverb that followed "go", used the dictionary to find the translation of a word that was clear to her in her native language and reread her text. She was able to make decisions based on her knowledge of the L2, which explains why she did not accept the translation provided by the dictionary and used another alternative of her own.

(9) But I would like to go ...for no pega to go ... beyond prejudice [checks the dictionary \& talks] desmontar el argument

... dismantle ... eso no me vale (3') [reads] and I would like to go beyond the prejudice [writes \& talks] and even turn it upside down.

[But I would like to go ... for it doesn't go ... go ... beyond prejudice [checks the dictionary \& talks] oppose the argument ... dismantle ... that's not good (3') [...]

Alicia rehearsed with different purposes, such as to find the most appropriate word or grammatical structure and to find the correct form of the word. In (10), she tried to decide based on her knowledge of the sound of the word; however, when unable to make a decision, she used the dictionary. Therefore, the compensation strategies of rehearsing, going by the sound and using the dictionary may be found together:

(10) [Talks and writes] Theirs is a ... (7') [talks] hypocritic hypocritable [checks the dictionary and talks] hypocritical, hypocritic no me pega. Ah sí, está bien ... hypocritical.

[talks] hypocritic hypocritable [checks the dictionary and talks] hypocritical, hypocritic doesn't sound familiar to me. Oh yes, it's fine ...hypocritical]

Dictionary use

Both the advanced and the less advanced learners in this study resorted to the bilingual Spanish-English dictionary to find solutions for their lexical problems, as reported in other studies with L2 learners (McDonough, 2001; Wolfersberger, 2003). Eva and Alicia used their bilingual dictionaries mainly to check spelling and appropriacy of meaning. Alicia used the dictionary 23 times and produced 1,937 words in the first and final drafts, whereas Eva did so 17 times and produced 911 words. 9 were distracting uses of the dictionary for Alicia (39.13\%) and 9 for Eva (52.94\%), because they forgot what they wanted to say and had to repeat, translate or go back to previous sections of their compositions to get their ideas back. However, unlike Eva, Alicia also used it to check the preposition that followed nouns, adjectives and verbs.

Again, in (11) Alicia used a cluster of strategies that supported each other, as concluded for other successful writers (Macaro, 2001; 2006) and that led to effective writing: she planned as she was writing, used the dictionary to check the translation of a word in her L1, guessed between two alternatives based on her L2 knowledge and reread the sentence she was working on before making a decision. This strategy cluster may in turn be connected with another strategy cluster pertaining to looking up a new word in the dictionary and this one to another related to memorizing the new word for future use (Macaro, 2006, p. 327).

(11) [Talks \& writes] When taking into consideration ... (4') the limited budgets young people ... [checks the dictionary \& talks] disponer "have available" podría servir o "have at their disposal"] [reads] When taking into account the limited budgets young people [writes \& talks] have at their disposal I truly think that it is preferable.

[checks the dictionary \& talks] have "have available" could be used or "have at their disposal"]

Rereading the text produced so far, the written assignment and the notes/outline

Alicia's and Eva's composing behaviour reveals that rereading the text produced so far (RRAWT), the written assignment (RRA) and the notes/outline (RRN/O) (also called "backtracking through the L2" for all three in Manchón et al.'s (2000a, p. 24) study) are compensation strategies employed by advanced and less advanced learners of English, who differ in their reading behaviors, such as number of readings, extension and purpose. While Alicia read extensively at the end of and during composing, Eva seldom reread or reflected on whole chunks of texts, but she merely concentrated on the sentence she was writing, as in Gaskill (1986).

Examination of Eva's protocol reveals that she reread her text, but she did so fewer times than Alicia, because she also backtranslated as a way of generating content (see Table 7). Thus, the tendency in both informants is that the greater the use of RRAWT, the less DT and vice versa, a conclusion also drawn in Manchón et al.'s (2000a) study. Indeed, Eva's rereadings concerned the text already produced to find a way of continuing (72\%). She also read her written notes, although she resorted to them few times (16\%), because she had not planned extensively for the content of her composition. Finally, she reread her assignment sheet on three occasions (12\%) to verify the arguments given and to copy them in her draft. Similarly, Alicia's rereadings were mostly rereadings of the text written so far $(82.14 \%)$, while only a modest percentage were rereadings of the assignment sheet and written notes/outline $(5.36 \%$ and $12.5 \%$, respectively). However, unlike Eva, she reread frequently and extensively while composing and at the end of her composition. She also reread small chunks of text while in the middle of putting her thoughts on paper. The relative distributions were tested with a chi-square test and were statistically significant $\left(X^{2}=5,991, \mathrm{df}=2, \mathrm{p}<.05\right)$.

TABLE 7.

USE OF REREADING THE ASSIGNMENT SHEET, THE NOTES OR OUTLINE AND THE ALREADY WRITTEN TEXT BY THE TWO INFORMANTS

\begin{tabular}{|l|l|l|l|l|}
\hline \hline & RR (A) & RR (N/O) & RR (AWT) & Total \\
\hline \hline Alicia & $6(5.36 \%)$ & $14(12.5 \%)$ & $92(82.14 \%)$ & 112 \\
\hline Eva & $3(12 \%)$ & $4(16 \%)$ & $18(72 \%)$ & 25 \\
\hline \hline
\end{tabular}


Revising extensively

Unlike Eva, Alicia made extensive revisions of her first draft, such as reorganizing the introduction, creating new paragraphs, moving others around and adding information to her text aiming at keeping up the standard attained when writing in her L1. Such extensive revisions happened combined with other strategies either simultaneously or in sequence, forming, thus, a strategy cluster:

(12) [Checks her $1^{\text {st }}$ draft $\&$ talks] (11') A ver, aquí voy a cambiar un poco porque no me gusta que un párrafo empiece por "I". [Writes \& talks] In favour of my opinion I will not make use of some arguments ... of some arguments that have been defended by consumers to support marijuana legalisation ... marijuana legalisation, like the claim that it does not create any dependence [talks] me salto un trozo porque es un poco superfluo I will only use some arguments like the claim de esto y de lo otro [talks \& copies] because they are mere hypotheses [...] [Checks her $1^{\text {st }}$ draft] (7') Vale.

[[Checks her $1^{\text {st }}$ draft \& talks] (11') Let's see, here I'll change it a little bit because I don't like a paragraph to start with "I". [...] [talks] I'll skip this part because it is a bit superfluous I will only use some arguments like the claim of this and that $[\ldots]\left[\right.$ Checks her $1^{\text {st }}$ draft $]\left(7^{\prime}\right)$ Ok.]

In (12) Alicia read her first draft before starting the task of rewriting the paragraph she was working on, rewrote some parts and eliminated others. She finished rereading her first draft again and, when she was happy with the result, she considered it finished.

On the subject of her revisions, Alicia related in the interview that she hardly ever deleted any of the ideas contemplated but, when necessary, she included new ones and tried to match them against the existing content. In contrast, Eva did not make any major revisions in her drafts but, instead, she concentrated on minor changes. Indeed, her first and final drafts were almost identical:

INTERVIEW: “...idéntico. Lo que puedas darte cuenta que no has hecho al principio, pero suele ser casi siempre el mismo."

[... identical. Wherever you have not done at the start, but it is almost always the same one]

VIDEOTAPE DATA: Isabel starts her sentences with an idea in mind; however, she often becomes distracted with minor problems, such as vocabulary and spelling conventions. Those "premature revisions" have however little, if any, positive effect.

L2 Strategies for completing the task within a given amount of time and without excessive cognitive effort

Going by the sound

Going by the sound is also a strategy that Alicia employed for solving lexical problems. By relying on the sound of words, Alicia was able to choose whether or not the words combined appropriately in the sentence, the exact form that a word took or the correct preposition, unlike less skilled writers who are more likely to resort to their L1:

(13) [Talks and writes] [...] I would also submit marijuana legalisation to the acceptance of legally ... (4') [talks] uff, qué feo

esto. [Reads] I would also submit marijuana legalisation to the ... [eliminates "of legally"] [talks \& writes] acceptance of rules and conditions $[\ldots]$

[[...] phew, how ugly it is.]

Since she was thinking aloud and writing, Alicia was able to judge how her words sounded. She reread the sentence she was working on and then revised. Thus, Alicia selected the strategies of going by the sound and rereading, which tailored the requirements of the task because she had found a dissonance between form and meaning. These strategies were preceded by planning and followed by revising. However, unskilled writers such as Eva use "revising by ear" less, that is, they do not make changes on the basis of what sounds "good" (Zamel 1983).

Coining words

In an attempt to retrieve the lexical items needed to express her intended meaning, Eva made use of an L1-based strategy: she coined one word similar to the one in her L1. In (14) below, when Eva tried to find a suitable word for "uso," she coined "consumition" and checked its appropriacy by retrieving different synonyms in her L1 ("consumición, consumo" [consumption]), by using the dictionary, and repeating. This type of lexical retrieval is similar to that reported by Wang (2003), which involved searching in the L1 and generating a range of synonyms.

(14) [talks] porque si el gobierno permite su uso ... [talks \& writes] if the government permits ... its freely ... [talks] its freely ... consumition? Consumición ... consumption [talks \& writes] con-sump-tion [checks the dictionary \& talks] consumición... consumption, yo diría consumo, consumo, consumption. OK. [writes] consumption [talks] consumption ... what? [she's forgotten what she wanted to say]

However, Eva's strategy orchestration was not successful because it did not contribute to fluent writing, as she forgot the meaning she wanted to express.

Guessing

Alicia also employed the compensatory strategy of guessing to make decisions about prepositions or the most appropriate verb in a sentence:

(15) [Talks \& writes] Legalising a substance ... (12') [non-audible] able to alter certain human states and about which ... 
[reads] Legalising a substance able to alter certain human states and about which ... [substitutes "about" for "of'] of which [talks \& writes] consequences may be unknown.

Closer study of the protocol reveals the use of a group of strategies that supported each other: planning, rereadings of the text under examination and guesses. These aided to keep Alicia's flow of composing going in a manner similar to advanced native English writers. In contrast, observations of the protocols and the video recordings suggest that Eva preferred not to guess. Instead, when in doubt about the spelling or the translation of a word, she resorted to the dictionary or her material.

Substituting a lexical item

When assessing a lexical choice, as in (16), Alicia retrieved another alternative in her L2, but, unlike in other studies (Wang 2003), when she doubted about its appropriateness or correctness in terms of meaning or use, she did not switch to her L1 for assessing and making a better choice. Instead, she had the cognitive ability to do so in her L2.

(16) [Talks \& writes] The opponents of marijuana legalisation also criticise it because they believe ... [reads] The opponents of marijuana legalisation also criticise it because they believe ... [writes \& talks] that it would ... (30') [reads silently \& talks] evoke no me gusta la palabra ... uy por favor no me sale la palabra ... [writes \& talks] it would have as a consequence that ...

[reads silently \& talks] evoke I don't like the word ... oh please I can't think of the word ... [writes \& talks] it would have as a consequence that ....]

Eva also substituted lexical items; however, she did so less often than Alicia and these were mostly words that she knew how to use such as "opinion" and "point of view", "cannabis" and "marijuana" and, thus, she did not need to resort to her L1 for assessing their suitability.

Reducing information and using a new grammatical structure

Alicia also eliminated information contained in her first draft when writing the final version of her composition, but she did so to write her essay within a reasonable period of time. On a few occasions she used a new grammatical structure; however, she did not simplify the syntax of her language as Uzawa \& Cumming's (1989) intermediate students did; instead, such changes seemed to be motivated by style concerns:

(17) [Reads] I would also submit marijuana legalization [talks] ay, esto lo cambio porque no quiero empezar un párrafo con "I";

entonces voy a decir [revises \& then writes] marijuana legalization should be submitted to the acceptance of rules and conditions $[\ldots]$.

[[Reads] I would also submit marijuana legalization [talks] ah, I'll change this because I don't want to start a paragraph with "I"; then, I'll say [...].

In contrast, Eva did not consider any grammar changes once her ideas were on paper. It was as if once the content was on paper, it could not be reconstructed anew.

Using line numbers rather than copying from her first draft

Alicia also displayed a strategy that helped her to keep her writing within certain time limits: she wrote down the line numbers of the content included in the first draft rather than copying. Such strategy allowed Alicia to make extensive revisions of her text, which included old parts from her first draft and new ones that she included in the second draft:

INTERVIEW: "No suelo borrar ninguna de mis ideas pero cuando es necesario incluyo nuevas y las trato de acoplar al contenido que ya tengo."

[I hardly ever delete any of the ideas contemplated but, when necessary, I include new ones and try to match them against the existing content]

\section{DISCUSSION}

The expert and less expert learners of English in this study often used very similar strategies to compensate for their missing knowledge. However, they differed in the total number of compensation strategies used and in how effective they were (see Table 8). As in Uzawa \& Cumming (1989), they followed two different tendencies: strategies for maintaining the same level of writing achieved in the L1 and strategies for completing the task within a given amount of time and without excessive cognitive effort. The intermediate writer Eva used the compensation strategies of repetition, translation of words and little phrases, rehearsing, going by the sound, rereading, backtranslation, dictionary use, guessing, substituting a lexical item, and coining words, but these did not result in good writing, because they were inappropriately orchestrated. In contrast, the more effective learner Alicia did not use translation, backtranslation and coining words and added using line numbers rather than copying as well as compensation strategies aimed at an organizational level, such as revising extensively, reducing information and using a new grammatical structure, which subsequently affected her choice of words. Also, she showed a careful orchestration of strategies leading to effective prose. For example, when using the dictionary (see examples 2 and 11 above) Alicia and Eva deployed different strategies and their results were results were also different (see Table 9). Therefore, these two different approaches suggest that successful orchestration of strategies served to distinguish between the two writers in this study and it was key to their success differences. It is however true that Alicia's and Eva's past writing experience and instruction may also explain their use of compensation strategies. Alicia's extensive writing experience in Spanish, English and German and the writing instruction received that focused on text content and organization no doubt influenced her into using 
effective compensation strategies. Also, she had practiced narrative, descriptive and argumentative essays and, thus, she was accustomed to dealing with tasks of varying difficulty ${ }^{4}$. However, the weaker learner Eva had had less writing experience and had received instruction that concentrated on the product rather than on the process, which may explain why she used simple compensation strategies or inefficient strategy clusters that did not result in good writing.

TABLE 8.

COMPENSATION STRATEGIES USED BY THE TWO INFORMANTS AND PURPOSES FOR USING THEM

\begin{tabular}{|c|c|c|c|}
\hline "Compensation strategies & Alicia & Eva & Purposes for using the strategies \\
\hline 1. Translation & 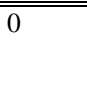 & 37 & $\begin{array}{l}\text { a. Checking that the words capture the writer's intended } \\
\text { meaning } \\
\text { b. Keeping the writer's flow of composing }\end{array}$ \\
\hline 2. Repetition & 25 & 72 & $\begin{array}{l}\text { a. Keeping the information in mind } \\
\text { b. Trying to find a way of continuing }\end{array}$ \\
\hline 3. Rehearsing & 18 & 15 & $\begin{array}{l}\text { a. Word-search } \\
\text { b. Finding the correct spelling of words }\end{array}$ \\
\hline 4. Dictionary use & 23 & 19 & $\begin{array}{l}\text { a. Checking spelling concerns } \\
\text { b. Grammatical accuracy } \\
\text { c. Word-search }\end{array}$ \\
\hline 5. Backtranslation & 0 & 38 & $\begin{array}{l}\text { a. Checking that the words capture the writer's intended } \\
\text { meaning }\end{array}$ \\
\hline 6. Rereading & 112 & 25 & $\begin{array}{l}\text { a. Comparing the text with the assignment sheet and the } \\
\text { outline } \\
\text { b. Keeping the flow of composing going }\end{array}$ \\
\hline 7. Guessing & 4 & 2 & a. Using the right spelling or word \\
\hline 8. Going by the sound & 9 & 1 & a. Finding the right word or expression \\
\hline 9. Substituting a lexical item & 22 & 10 & $\begin{array}{l}\text { a. Finding a better word that matches the writer's intended } \\
\text { meaning }\end{array}$ \\
\hline 10. Coining words & 0 & 2 & $\begin{array}{l}\text { a. Writing out a word the spelling of which the writer is } \\
\text { unsure of }\end{array}$ \\
\hline 11.Using a new grammatical structure & 6 & 0 & $\begin{array}{l}\text { a. Using the correct grammatical structure } \\
\text { b. Using the grammatical structure that best expresses the } \\
\text { writer's intended meaning. }\end{array}$ \\
\hline 12. Revising extensively & 11 & 0 & $\begin{array}{l}\text { a. Grammatical accuracy } \\
\text { b. Checking that the text says what the writer intends } \\
\text { c. Reorganising content or the structure of the text }\end{array}$ \\
\hline 13. Reducing information & 1 & 0 & a. Completing the composition within the given time \\
\hline $\begin{array}{l}\text { 14. Using line numbers rather than } \\
\text { copying from the first draft }\end{array}$ & 3 & 0 & a. Completing the composition within the given time \\
\hline TOTAL: & 234 & 221 & \\
\hline
\end{tabular}

TABLE 9.

ALICIA'S AND EVA'S STRATEGY USE WHEN RETRIEVING A LEXICAL ITEM

\begin{tabular}{|l|l|l|}
\hline \hline Problem & Alicia & Eva \\
\hline \hline Lexical retrieval & Metacognitive strategy: & Metacognitive strategy: \\
& Planning & \\
& & Planning \\
& Compensation strategies: & - Translating \\
& - Using the dictionary & - Word coining \\
& - Guessing between two alternatives & - Backtranslating \\
& - Rereading the sentence/paragraph & - Translating \\
& Cognitive strategy: & - Using the dictionary \\
& Deduction (conscious application of & - Using synonyms in the L1 \\
& rules by using her L2 knowledge) & \\
\hline \hline
\end{tabular}

Repetition, rehearsing (Raimes, 1985, 1987; Wolfersberger 2003), dictionary use (Wolfersberger, 2003), guessing, going by the sound, substituting a lexical item and using line numbers rather than copying may contribute to assist L2 learners to compensate for lack of linguistic knowledge in their L2. Nonetheless, repetition, rehearsing and dictionary use seem to work well if the learners know their intended meaning and resort to them to find the right words or as a strategy that helps them to plan how to continue. Both Eva and Alicia rehearsed, repeated and checked the dictionary throughout their composing and they both had similar purposes; however, only Alicia was able to deploy efficient strategy clusters. It seems that her higher proficiency allowed her to "choos[e] and evaluat[e] from a range of strategies, [which was] more effective than linear deployment of several strategies" (Macaro, 2006, p. 328), more typical of the inexperienced learner Eva. Macaro concluded that orchestration of strategies suggests that the writer has a higher level

\footnotetext{
${ }^{4}$ Grabe (2001) proposed five levels of writing purpose, which were conceived as levels of difficulty from Level 1 (lowest) to Level 5 (highest) and, thus, writers need to have mastered one level of the hierarchy to be able to write texts of the following level. Argumentative essays are situated at Level 5.
} 
of metacognition. This result coincides with those of Porte's (1995) and Macaro's (2001), who also concluded that their young learners used individual strategies that were not appropriately orchestrated. For example, Porte (1995) found that a subvocalizing strategy was counterproductive when copying sentences in some subjects, while Macaro (2001) concluded that applying prior knowledge of the topic was ineffective in a reading task when his subjects did not combine it with evidence found later in the text.

Other strategies work well for advanced learners, such as rereading the AWT for local or global purposes, RRA and RRN/O. Alicia made extensive use of RRAWT, because she did not backtranslate from her L2 back into her L1. Eva, however, made a large number of direct translations and very little rereading. Thus, there is an inverse correlation between number of RRAWT and number of DT. It may be possible to explain the differences in rereading and backtranslation behaviors by positing that they both presented very different composing behaviors, although they were both interested in communicating meaning. Indeed, Alicia wrote her L2 text fluently from sentence to sentence and within the sentence in a manner similar to native English writers, whereas for Eva generating content in English supposed a strenuous effort and had to resort to translating from her L1 into her L2.

Closer examination of the subjects' writing behaviours reveals that the variable "dominant language" in the L2 composing process has also proved to influence the differences in rereading and backtranslation behavior, as pointed out in Manchón et al. (2000a, p. 31). Eva was the informant that used the least English while composing (43\%) and she was also the one that reread the least in the L2 (25 rereadings versus 112 for Alicia). In contrast, Alicia used more English in her writing (over 61\%) and was the one that reread the most in the L2. Thus, this study also concludes that the more use of the L1 in the composing process, the more use of the L1 while rescanning. However, unlike Manchón et al.'s investigation, the present study also finds that the more use of the L2 in the composing process, the more use of the L2 while rescanning. This difference may be due to the fact that in Manchón et al.'s study the informants were all intermediate English students, whereas Alicia was an advanced learner and, therefore, she had a higher proficiency level.

Eva translated from Spanish into English while planning to maintain the same level of writing attained in her L1. This translation was only possible because she used her immediate knowledge of the L2, which was the quickest and most accurate way of producing text. Eva translated, repeated, coined words and substituted lexical items; however, these strategies were deployed in a linear fashion and, thus, they did not contribute to a good quality product. In contrast, the more advanced writer Alicia did not use translation at all, because her higher L2 proficiency helped her to write in her L2. It seems that translation is valid for those writers whose L2 is not high enough to write completely in English, but is not low enough to write one draft in their L1 and then translate it into English (Wolfersberger, 2003, p. 9).

Backtranslating serves the purpose of verifying that the text conveys the ideas that the writer plans to communicate, as pointed out in different investigations (Manchón et al., 2000a; Wolfersberger, 2003). It seems that students feel more at ease with the words they have selected by backtranslating them into their L1, as observed in Wang (2003, p. 361). This strategy brings more benefits since backtranslation of their L2 texts helps novice learners to find new ways of continuing, the process does not come to a stall and, thus, learners need to look for their own words. This study may contribute to refine Manchón et al.'s (2000a) study on backtracking through the writers' L1, since the advanced learner Alicia was found not to use backtranslation at all and to employ a more sophisticated strategy than Manchón et al.'s intermediate students, given that the subject not only had to paraphrase content in her L2 and transform it into a new version, but she also had to select the parts of the text that were more relevant and omit other information by using her L1. This finding may be explained by the fact that argumentative essays are more cognitively demanding (Cumming, 1989 ) and, thus, L2 learners make use of their linguistic resources in their composing (which are wider than those of the monolingual learner) and are brought to bear in processes such as backtranslation (Manchón et al., 2000a). In contrast, Eva worked at a simpler level due to her lower proficiency: she made direct translations of small segments of text to verify the meaning expressed and to generate further content, but made no attempts to make more complex backtranslations. Given the very small number of informants in this study, future research needs to ascertain whether or not these results apply with other successful and unsuccessful learners, other text types and purposes for backtranslating.

\section{CONCLUSIONS AND LIMITATIONS OF THE STUDY}

The advanced and the less advanced learners were found to use very similar strategies to compensate for their missing knowledge, but they often differed in the how they deployed them. Not only did the better writer employ the majority of strategies that Eva had used, but she also used others that helped her to put her words onto paper. Indeed, Alicia showed a careful orchestration of strategies that were appropriate to the task at hand. Eva, however, worked at a simpler level and used several strategies that were presented in a linear fashion and did not result in effective prose.

One limitation of this study is the small sample of participants, which make it difficult to generalize the results. Also, the time-compressed nature of the task is a further limitation and, thus, the results may differ in other contexts. Finally, the use of the think-aloud protocol may have had an impact on the writers' strategy use, since the procedure may have overloaded their memory. Although it may be problematic to draw conclusions from this experiment for classroom practice, writing teachers need to discuss the compensation strategies used by advanced learners, including repetitions and going by the sound, as they are proof of their usefulness during L2 writing. Teachers may also encourage students to use strategies aiming at maintaining the same level attained in their L1 through exercises that require students to develop their own content and to make extensive revisions of their texts. 
For future study, a larger number of participants may be employed to see if the results can be made extensive to other advanced and less advanced learners of English and of other languages. It could also be interesting to see whether or not the students use the same strategies in naturalistic contexts, where students are not required to write within a given time. Finally, some students may be trained to use compensation strategies and to check whether or not they contribute to effective writing.

\section{REFERENCES}

[1] Ardnt, V. (1987). Six writers in search of texts: A protocol based study of L1 and L2 writing. ELT Journal 41, 257-267.

[2] Beare, S. and Bourdages, J. S. (2007). Skilled writers' generating strategies in L1 and L2: An exploratory study. In G. Rijlaarsdam et al. (ed.), Studies in Writing Vol. 20, Writing and Cognition: Research and Applications. Amsterdam: Elsevier, $151-161$.

[3] Beraiter, C. and Scardamalia, M. (1987). The psychology of written composition. Hillsdale, NJ: Erlbaum.

[4] Carson, J.E., Carrel, P.L., Silverstein, S., Kroll, B., and Kuehn, P.A. (1990). Reading-writing relationships in first and second language. TESOL Quarterly 24, 245-266.

[5] Cumming, A. (1989). Writing expertise and second language proficiency. Language Learning 39, 81-141.

[6] Cumming, A., Rebuffot, J. and Ledwell, M. (1989). Reading and summarizing challenging texts in first and second languages. Reading and Writing: An Interdisciplinary Journal 2, 201-219.

[7] Cumming, A. (1990). Metalinguistic and ideational thinking in second language Composing. Written Communication 7, 482511.

[8] Educational Testing Service. (1995). TOEFL Test Exercise Book. TOEFL Preparation Kit. USA.

[9] Ericsson, K. A. and Simon, H. A.. (1993). Protocol Analysis: Verbal Report as Data. Cambridge, MA: MIT Press.

[10] Gaskill, W. H. (1986). Revising in Spanish and English as a Second Language: A Process-Oriented Study of Composition. PhD Dissertation, University of California.

[11] Grabe, W. (2001). Notes toward a theory of second language writing, in T. Silva \& P. K. Matsuda (eds.). On second language writing. Mahwah, NJ: Erlbaum, 39-57.

[12] Jacobs, H. L. et al. (1981). ESL composition profile, in Testing ESL Composition: A Practical Approach. English Composition Program. Rowley, MA: Newbury, 30-32.

[13] Jones, C. S. and J, Tetroe. (1987). Composing in a second language, in A. Matsuhashi (ed.). Writing in a Real Time: Modelling the Production Processes. Norwood, NJ: Ablex, 34-57.

[14] Laufer, B. and P. Nation. (1995). Vocabulary size and use: lexical richness in L2 written production. Applied Linguistics 16, 307-322.

[15] Li, Y. (2000). Linguistic characteristics of ESL writing in task-based e-mail activities. System 28, 229-245.

[16] Macaro, E. (2001). Learner strategies in second and foreign language classrooms. London: Continuum.

[17] Macaro, E. (2006). Strategies for language learning and for language use: Revising the theoretical framework. The Modern Language Journal 90, 320-337.

[18] Manchón, R. M. (2001). Trends in the conceptualization of second language composing strategies: A critical analysis. International Journal of English Studies 1, 47-70.

[19] Manchón, R. M., Roca de Larios, J. and Murphy, L. (2000a). An approximation to the study of backtracking in L2 writing. Learning and Instruction 10, 13-35.

[20] Manchón, R. M., Roca de Larios, J. and Murphy, L. (2000b). La influencia de la variable "grado de dominio de la L2 en los procesos de composición en lengua extranjera: Hallazgos recientes de la investigación. In C. Muñoz (ed.) Segundas Lenguas: Adquisición en el Aula. Barcelona: Ariel Linguiística, 277-297.

[21] McDonough, J and McDonough, S. (2001). Composing in a foreign language: An insider-outsider perspective. Language Awareness 10, 233-247.

[22] Murphy, L. and Roca de Larios, J. (2010). Searching for words: One strategic use of the mother tongue by advanced Spanish EFL Writers. Journal of Second Language Writing 19, 61-81.

[23] Oxford, R. L. (1990). Language Learning Strategies: What Every Teacher Should Know. New York: Newbury House.

[24] Oxford, R.L. (2003). Language learning styles and strategies: concepts and relationships. International Review of Applied Linguistics and Language Teaching 41, 271-278.

[25] Oxford, R. L., Cho, Y., Leung, S. and Kim, H. Y. (2004). Effect of the presence and difficulty of task on strategy use: an exploratory study. International Review of Applied Linguistics and Language Teaching 42, 1-47.

[26] Pennington, M.C. and So, S. (1993). Comparing writing process and product across two languages: A study of 6 Singaporean university student writers. Journal of Second Language Writing 2, 41-63.

[27] Porte, G. K. (1995). Writing wrongs: Writing as a strategy for underachieving EFL writers. ELT Journal 49, 144-151.

[28] Raimes, A. (1985). What unskilled writers do as they write: A classroom study. TESOL Quarterly 19, $229-258$.

[29] Raimes, A. (1987). Language proficiency, writing ability, and composing strategies: A study of ESL college student writers. Language Learning 37, 439-467.

[30] Roca de Larios, J., Manchón, R. M., and Murphy, L. (2008). The foreign language writer's strategic behaviour in the allocation of time to writing processes. Journal of Second Language Writing 17, 30-47.

[31] Roca de Larios, J., Marín, J. and Murphy L. (2001). A temporal analysis of formulation processes in L1 and L2 writing. Language Learning 51, 497-538.

[32] Sasaki, M. (2004). A multiple-data analysis of the 3.5 year development of EFL student writers. Language Learning 54, 525582.

[33] Sasaki, M. and Hirosi, K. (1996). Explanatory variables for EFL students' expository writing. Language Learning 46, $137-174$.

[34] Swain, M. and Lapkin, S. (1995). Problems in output and the cognitive processes they generate: A step towards second language Learning. Applied Linguistics 17, 210-233. 
[35] Uzawa, K. and Cumming, A. (1989). Writing strategies in Japanese as a foreign language: Lowering or keeping up the standards. Canadian Modern Language Review 46, 178-194.

[36] van Weijen, D., van den Bergh, H., Rijlaarsdam, G. and Sanders, T. (2009). L1 use during L2 writing: An empirical study of a complex phenomenon. Journal of Second Language Writing 18, 235-250.

[37] Wang, L. (2003). Switching to first language among writers with differing second-language proficiency. Journal of Second Language Writing 12, 347-375.

[38] Whalen, K. and Ménard, N. (1995). L1 and L2 writer's strategic and linguistic knowledge: A model of multiple-level discourse Processing. Language Learning 45, 381-481.

[39] Wolfersberger, M. (2003). L1 to L2 writing process and strategy transfer: a look at lower proficiency writers. TESL-EJ 7 , http://tesl-ej.org/ej26/a6.html (accessed 2/2/2011).

[40] Woodall, B. R. (2002). Language-switching: using the first language while writing in a second language. Journal of Second Language Writing 11, 7-28.

[41] Yau, M. (1991). The role of language factors in second language writing. In L. Malave and G. Duquette (eds.). Language, Culture and Cognition. Clevedon: Multilingual Matters, 266-283.

[42] Zamel, V. (1983). The composing processes of advanced ESL students: Six case studies. TESOL Quarterly 17, 165-187.

Ana Belén Cabrejas-Peñuelas is an Associate Professor at the University of Valencia, Spain, where also received her PhD degree. Her research has mainly focused on the revision processes of native and non-native English writers, L2 writing strategies and the use of the $\mathrm{L} 1$ while composing in a second language. 